\title{
2016 U.S. Presidential Election and Stock Markets in China
}

\author{
SingRu Hoe ${ }^{1} \&$ Srinivas Nippani ${ }^{1}$ \\ ${ }^{1}$ Department of Economics and Finance, Texas A\&M University-Commerce, U.S. \\ Correspondence: SingRu Hoe, Department of Economics and Finance, Texas A\&M University-Commerce, P. O. \\ Box 3011, Commerce, TX 75429-3011, U.S. Tel: 903-886-5680. E-mail: Celine.Hoe@ tamuc.edu
}

Received: April 14, 2017

Accepted: May 6, 2017

Online Published: May 30, 2017

doi:10.5539/ijef.v9n7p32

URL: https://doi.org/10.5539/ijef.v9n7p32

\begin{abstract}
This study seeks to address the question if the 2016 U.S. Presidential election and Mr. Donald Trump's path to U.S. presidency affected the stock market returns in China. We do not find conclusive results from three leading stock indices of China, SHCOMP, SZCOMP, and SHSZ300. There is an immediate impact shown in SHSZ300, but not in SHCOMP and SZCOMP. We ascribe this to the impact of less sophisticated investors who dominate the stock market in China and also to that country's censorship of the media wherein the government could effectively either block or downplay the unfavorable information.
\end{abstract}

Keywords: presidential election, campaign promise, stock market

\section{Introduction}

Donald J. Trump's announcement speech of his bid for the President of the United States on June 16, 2015 was criticized as overly sensationalized, casting strong opposition, doubts and worries even within the Republican Party itself. As Mr. Trump's campaign advanced closer toward securing the Republican nomination, the concerns started to spread across other countries including China, which is both the largest creditor and trade partner of the United States. The supposed unpredictability of Mr. Trump posed serious challenges to the Chinese government in several aspects. According to conventional wisdom, his proposition of imposing steep tariffs on imported goods as well as his controversial comment about getting creditors of the U.S. government to accept less for their debt than they are owed would probably hurt the economy in China should Mr. Trump be elected. Consequently, it is reasonable to suspect that major developments leading to increases in chances of Mr. Trump's path to the U.S. presidency would upset the stock market in China due to investors' pessimistic expectation of future economy.

On the other hand, according to several articles in the popular press the Chinese stock markets are very volatile because they are dominated by mom-and-pop investors (Note 1) who tend to follow trends, herd into stocks and are famous for evaluating stocks from unconventional angles. In such a market, technical analysis rather than fundamental analysis plays a major role in stock market movements. It is thus possible that Mr. Trump's growing strength of candidacy as well as his final victory, which signals a potentially gloomy economic outlook for China, would not play any important role on the stock market in China. Also, China's censorship of the media could effectively downplay any "undesirable" information, thus insulating its stock markets from the hit expected to follow.

Given two opposing viewpoints mentioned above, this study attempts to address the question of whether Mr. Donald Trump's progressive advance of the U.S. presidency would negatively hit the stock market in China. We investigate the issue by examining the stock market performance in China following two major developments: the first is Mr. Trump's status in the leapfrogging other contenders for the nomination as the Republican candidate for the presidency, and the second is his unexpected victory contrary to popular polls in the presidential race on November 8, 2016. An abundance of literature exists on studying the relations between presidential elections and the behavior of stock markets (see for example, Niederhofer, Gibbs, \& Bullock, 1970; Allvine \& O'Neill, 1980; Huang, 1985; Pantzalis, Stangeland, \& Turtle, 2000; Nippani \& Medlin, 2002; Nippani \& Arize, 2005; Li \& Born, 2006; Huang, 2011, 2013; Goodell \& Bodey, 2012). While a few studies focus on how U.S. presidential elections might impact stock markets in other countries (Foerster, 1994; Foerster \& Schmitz, 1997; Nippani \& Arize, 2005; Huang, 2013), none of these examines the impact of the election on China's stock markets. This study contributes to the literature looking into the effect of U.S. presidential election 
of 2016 on the stock market in China. We investigate the impact of the GOP presidential candidate and the final nominee, Mr. Donald J. Trump, who caught the greatest concerns of Chinese government due to his wildcard campaign promises which pose serious challenges to Chinese government and would potentially harm the economy in China.

We do not find conclusive evidence that the U.S. presidential election has immediate impacts on the stock markets in China. There is no immediate impact shown in two of three leading stock indices of China, Shanghai Stock Exchange Composite Index (SHCOMP) and Shenzhen Stock Exchange Composite Index (SZCOMP), but it does display immediate impact in Shanghai Shenzhen CSI 300 Index (SHSZ300). The testing results from SHCOMP and SZCOMP might be explained by the belief that majority of Chinese stock speculators are mom-and-pop investors whose investment strategies are not based on fundamentals, and that China's censorship of the media might insulate its stock markets from influences spilling over from the U.S. presidential election. For the test result from SHSZ300, the market reacted negatively to Senator Ted Cruz's exit from the Republican primary race, a major event leading to Mr. Trump's path to the U.S. presidency. We also find that the market reacted positively to Mr. Trump's obtaining the minimum number of pledged delegates to claim the nomination and Mr. Trump's final victory. The negative market response from Mr. Cruz's withdrawal could be justified both regarding "pessimistic" expectation of future economy following the news or regarding transmission of "negative" sentiments from some unconventional angles. The latter explanation could better justify the positive market response to the two later events, and that "fundamentals" do not matter for mom-and-pop investors could be illustrated from the changes in share prices observed in two companies on the day after Mr. Trump's victory where "phonics" is all that mattered:

"The share price of Wisesoft Co. listed on the small-and medium sized enterprise board on the Shenzhen Stock Exchange soaring by as much as 9.7\% is because Wisesoft's Chinese name, pronounced Chun Da Zhi Sheng, sounds like "Trump wins with wisdom. The share price of Yunnan Xiyi Industrial falling by the daily trading limit of 10\% because in Mandarin, Xi Yi sounds similar to "Aunt Hilary", a popular nickname for Mrs. Clinton on the Chinese Internet." (Note 2)

In fact the "phonics" phenomenon is not first shown in this latest presidential election; the following is another example occurred on the day Mr. Barack Obama secured reelection in 2012:

"The shares of Aucma Co., a little known electronics producer, turned from an early loss of $2 \%$ to a $5 \%$ gain, closely tracking the drumbeats of exit polls. The reason: Acuma's name in Chinese pronounced as "Aokema" is auspiciously close to Mr. Obama's "Aobama." (Note 3)

Using the testing result from SHSZ300, we might say 2016 U.S. presidential election impacted the stock market in China with evaluations from unconventional angles; therefore, the resulting impact might not be as expected from rational expectations based on fundamental analysis.

The remainder of the paper is organized as follows. In Section 2, we give a brief literature review. In Section 3, we detail the methodology. In section 4, empirical findings are stated, and we present concluding remarks in Section 5.

\section{Literature Review}

The topics regarding the influence of presidential elections on the stock market have received widespread attention among academics. One theme of the studies focuses on the effect of the presidential election cycle on the behavior of the stock market, identifying the pattern of stock markets shown in response to presidential elections. For example, Allvine and O'Neill (1980) studied the stock market returns and the presidential election cycle over the period of 1900 to 1979 . They found a four-year pattern during the period studied with a clear relationship between stock returns and presidential elections. Huang (1985) studied common stock returns over the four-year election cycle in respect to different administrations. Consistent with Allvine and O'Neill (1980), he found a four-year pattern which is more pronounced in more recent periods. Foerster (1994) studied the impact of Canadian and U.S. elections on stock markets in Canada and found a four-year pattern. They also found that Canadian markets react even stronger to U.S. regime changes.

The other theme of studies focuses on studying stock returns in the days and weeks surrounding presidential elections. Niederhofer, Gibbs, and Bullock (1970) examined the Dow-Jones Index surrounding Presidential Election Day over the period of 1900 to 1968 in the United States, finding ebullient market during the pre-election period and post-election period. Also, they evidenced that the market would prefer Republicans to Democrats. Pantzalis, Stangeland, and Turtle (2000) studied the behavior of stock market indices across 33 countries around political election dates during the sample period over 1974 to 1995, and found a positive 
abnormal return during the pre-election period. Nippani and Medlin (2002) investigated the impact of 2000 U.S. presidential elections on three indices, Dow-Jones Index, S\&P 500, and NASDAQ. They found the market was adversely affected following the Election Day due to the delay in "winner" announcement and found no significant difference in the performance of the U.S. indices in the period when a winner was declared. Nippani and Arize (2005) examined the impact of the delay in the declaration of a winner in 2000 U.S. presidential election on the leading Mexican and Canadian stock indices. They found the results were consistent with those reported in Nippani and Medlin (2002). Goodell and Bodey (2012) examined price-earnings ratios of the S\&P 500 firms around U.S. presidential elections and found that stock market valuations would be negatively relate to the lessening of election uncertainty.

As to our knowledge, there is no literature investigating the potential connection between U.S. presidential elections and the stock market reaction in China. We are motivated to fill this gap by studying the effect of U.S. presidential elections on the stock market in China through 2016 U.S. presidential election. This is especially true in case of the 2016 election as Mr. Trump had made several promises with regard to how he would handle trade with China should he be elected.

\section{Methodology}

\subsection{Data}

The leading stock indices of China, Shanghai Stock Exchange Composite Index (SHCOMP), Shenzhen Stock Exchange Composite Index (SZCOMP), and Shanghai Shenzhen CSI 300 Index (SHSZ300), and MSCI World Index over the period of May 2015 to December 2016 are retrieved from the Bloomberg database.

\subsection{Event and Hypothesis}

In this study, the event of interest is how the stock market in China reacted to the Mr. Donald Trump's progressive advance of the U.S. presidency. As the strength of Mr. Trump's candidacy grew, the chance that Mr. Trump's propositions adversely affecting future economy in China will get implemented should increase. We thus test the hypothesis:

$\mathrm{H}_{\mathrm{o}}$ : The immediate impact on the Chinese stock market would be negative.

We divide this entire event into three separate event windows. Event window 1, staring from May 4, 2016 and ending on May 10, 2016, refers to the first five trading days after Sen. Ted Cruz formally withdrew his candidacy for the Republican presidential nomination. Mr. Cruz's exit from the Republican primary race after loss in Indiana cleared the path for Mr. Trump to clinch the GOP nomination. This is the period during which Mr. Trump's "almost sure" candidacy for president as the Republican nominee was extensively discussed, his controversial campaign promises were broadly reexamined, and events that his campaign reassured and extended his earlier controversial or noncontroversial proposals were widely disseminated in the national and international media. Thus, this is the period sending out a strong signal that Mr. Trump's proposals adversely impacting the economy in China might become true shortly.

Event window 2, starting from May 27, 2016 and ending on June 2, 2016, refers to the first five trading days after Mr. Trump formally secured the Republican presidential nomination by passing the minimum amount of delegates required. At this point, Mr. Trump's candidacy for president as the Republican nominee was strongly confirmed. This is the period during which several similar events related to Mr. Trump's final nomination were discussed on a daily basis in the national media. The signal transmitted is that the chance that Mr. Trump's campaign promises adversely affecting the economy in China might become true shortly increases substantially.

Event window 3, staring from November 9, 2016 and ending on November 15, 2016, is the first five trading days following the Election Day when Mr. Trump officially won the presidency. This is the period during which events related to the election result and post-election analyses were discussed in the media. At this point, Mr. Trump's campaign promises adversely affecting the economy in China would be implemented and the uncertainty is only the degree of severity and when it would start.

\subsection{Methodology}

Conventional t-tests and a dummy variable regression that controls for the daily percentage returns on MSCI world index are used to examine the impact of events on the leading stock indices of China. Specifically, the regression equation performed is given as follows:

$$
\begin{gathered}
\text { Daily Index Return }=\beta_{0}+\beta_{1} \text { Event window } 1+\beta_{2} \text { Event window } 2 \\
+\beta_{3} \text { Event window } 3+\beta_{4} \text { DRMSCI }+\epsilon
\end{gathered}
$$

where Daily Index Return is the daily percentage returns on SHCOMP, SZCOMP or SHSZ300, Event window 1, 
Event window 2, and Event window 3 are binary variables that take the value of 1 for the event days to which they refer, zero otherwise, and DRMSCI is the daily percentage returns on MSCI world index. The variable " $\epsilon$ " is random and assumed normal with $\mathrm{E}(\epsilon)=0$. The regression is calculated beginning on May 4, 2015, and ending on December 31, 2016.

We test for heteroskedasticity and serial correlation by Breusch-Pagan-Godfrey test and by Breusch-Godfrey serial correlation LM Test respectively. Newey-West estimator is used when both heteroskedasticity and autocorrelation are presented, and White correction estimator (White heteroskedasticity-consistent standard errors) is used when there is no autocorrelation, but heteroskedasticity is suspected although the regression model passes Breusch-Pagan-Godfrey test.

Simple two-sample t-tests and non-parametric Mann-Whitney tests are performed to compare daily returns on SHCOMP, SZCOMP, and SHSZ300 with that on MSCI world index over the entire event period.

\section{Empirical Findings}

The results of regression analysis for equation (1) are presented in Table 1 below. The results for SHCOMP and SZCOMP are presented in panel A and C. In both indices, all event windows do not have statistically significant coefficients. We reject the hypothesis for the tests of SHCOMP and SZCOMP. That is, the test results show that the U.S. presidential election does not have an immediate impact on the stock markets in China. We conjecture that the results may be explained by two facts specific to Chinese stock market. First, mom-and-pop investors account for the majority of stock speculators and they seem to trade sentimentally based on technical analysis, following trends and herding into stocks, and are famous for evaluating stocks from unconventional angles. Information regarding fundamentals does not matter and thus the future gloomy economy outlook brought up by Mr. Trump's campaign promise would have no influence in their investment behavior. Second, China is known for its censorship of the media. It could choose either to downplay or to block the "negative" information. As a result, the behavior of its stock markets could be well insulated from influences spilling over from the U.S. presidential elections. Its censorship of the media could also help explain that its stock markets did not experience the huge hit as its neighboring Asian countries immediately after Mr. Trump's election win in the U.S.

The results for SHSZ300 are presented in panel B of Table 1. Event window 1 has a coefficient of -0.857385 with a t-statistic value of -2.436205 , significant at 0.05 level, event window 2 has a coefficient of 0.737620 with a t-statistic value of 2.696359 , significant at 0.01 level, and event window 3 has a coefficient of 0.345722 with a t-statistic value of 2.003546, significant at 0.05 level. We fail to reject the hypothesis for the test of SHSZ300. That is, the testing results indicate that the U.S. presidential election has an immediate effect on Chinese stock markets. The market reacted negatively to Sen. Ted Cruz's exit from the Republican primary race (event window 1), a major leapfrog of Mr. Trump's path to the U.S. presidency, but the market reacted positively to Mr. Trump's obtaining the minimum number of pledged delegates to claim the nomination (event window 2 ) and Mr. Trump's final victory (event window 3). The test results differ from those presented in SHCOMP and SZCOMP and fundamentals can be used to explain one of these results. There are two plausible explanations of the negative market response to Mr. Cruz's exit. First, it could be supported by investors' "pessimistic" expectation of future economy brought up by Mr. Trump's campaign promise. Second, it could also be justified as the transmission of "negative" sentiments from some unconventional angles in which "fundamentals" do not matter. The second explanation could also be applied to the justification of the positive market response to Mr. Trump's obtaining the minimum number of pledged delegates to claim the nomination and Mr. Trump's final victory. Therefore, even if the outlook of future economy may seem to be woeful, the market still reacted positively.

Table 1. Regression analysis

\begin{tabular}{lcc}
\hline & \multicolumn{2}{c}{ Independent Variable } \\
\cline { 2 - 3 } & & Parameter (Std. Error) \\
\hline Panel A: SHCOMP & & $\mathrm{t}$-value \\
Intercept & $-0.079123(0.096667)$ & -0.818516 \\
Event window 1 & $-1.038625(0.660036)$ & -1.573589 \\
Event window 2 & $0.794886(0.623991)$ & 1.273875 \\
Event window 3 & $0.376239(0.361273)$ & 1.041425 \\
DRMSCI & $0.574705(0.146562)$ & $3.921246^{* * *}$ \\
R-Square $=0.061821, \mathrm{~N}=435$ & & \\
\hline
\end{tabular}




\begin{tabular}{|c|c|c|}
\hline \multicolumn{3}{|l|}{ Panel B: SHSZ300 } \\
\hline Intercept & $-0.078017(0.096043)$ & -0.812314 \\
\hline Event window 1 & $-0.857385(0.351935)$ & $-2.436205^{* *}$ \\
\hline Event window 2 & $0.737620(0.273561)$ & $2.696359^{* * *}$ \\
\hline Event window 3 & $0.345722(0.172555)$ & $2.003546^{* *}$ \\
\hline DRMSCI & $0.590855(0.182261)$ & $3.241809^{* * *}$ \\
\hline \multicolumn{3}{|l|}{ R-Square $=0.063404, \mathrm{~N}=435$} \\
\hline \multicolumn{3}{|l|}{ Panel C: SZCOMP } \\
\hline Intercept & $-0.045400(0.112033)$ & -0.40524 \\
\hline Event window 1 & $-1.323239(1.032900)$ & -1.281091 \\
\hline Event window 2 & $1.082797(1.032873)$ & 1.048335 \\
\hline Event window 3 & 0.377087 (1.033009) & 0.365037 \\
\hline DRMSCI & $0.672369(0.132401)$ & $5.078264^{* * *}$ \\
\hline \multicolumn{3}{|l|}{ R-Square $=0.062562, \mathrm{~N}=435$} \\
\hline
\end{tabular}

Table 2 below compares the event period returns for the three indices with the MSCI world index using a t-test (Panel A) and a Mann-Whitney test (Panel B). All the results indicate that the MSCI world index has a return that is not significantly different from the three indices.

Table 2. Returns relative to MSCI world index

\begin{tabular}{|c|c|c|c|c|}
\hline Index & $\mathrm{N}$ & Mean & Standard Deviation & t-value \\
\hline \multicolumn{5}{|c|}{ Panel A: t-test on daily returns relative to MSCI World Index } \\
\hline MSCI & 140 & 0.032 & 0.774 & \\
\hline SHCOMP & 140 & 0.062 & 0.848 & 0.31 \\
\hline SHSZ300 & 140 & 0.061 & 0.824 & 0.30 \\
\hline SZCOMP & 140 & 0.09 & 1.16 & 0.47 \\
\hline \multicolumn{5}{|c|}{ Panel B: Mann-Whitney test } \\
\hline & $\mathrm{N}$ & Median & $\mathrm{W}$-value & \\
\hline MSCI & 140 & 0.0340 & & \\
\hline SHCOMP & 140 & 0.0784 & 19838.5 & \\
\hline SHSZ300 & 140 & 0.0731 & 19581.5 & \\
\hline SZCOMP & 140 & 0.1597 & 20401.0 & \\
\hline
\end{tabular}

\section{Conclusion}

This study examines if the 2016 U.S. Presidential election impacted the behavior of stock markets in China. There is no conclusive evidence that 2016 U.S. presidential election affected Chinese stock markets. Two of three leading stock indices of China, SHCOMP and SZCOMP, do not show immediate impact, but it does display immediate impact in SHSZ300. We propose two possible explanations of "no effect" and the partial rejection of our hypothesis. First, it is justified by the special characteristic of Chinese stock market in which majority of stock speculators dances to a different tune from fundamental valuations. The "pessimistic" expectation of future economy brought up by Mr. Trump's campaign promise would not occupy much in their mindshare, thus affecting their investing decisions. This justification is also well suited for reasoning the positive market response to Mr. Trump's obtaining the minimum number of pledged delegates to claim the nomination and Mr. Trump's final victory. The supposed unsophisticated investors as referred to in the popular press reacted to the information from these two events, but they interpreted the information set from non-conventional angles, where fundamentals did not matter. Second, it could also be explained by China's censorship of the media which could effectively insulate its stock markets from influences spilling over from the U.S. presidential elections by blocking or downplaying the undesirable information. Future studies can look into how President Trump's policies actually impact the Chinese stock markets.

\section{References}

Allivine, F. C., \& O'Neill, D. E. (1980). Stock Market Returns and the Presidential Election Cycle /Implications for Market Efficiency. Financial Analysts Journal, 36, 49-56. http://dx.doi.org/10.2469/faj.v36.n5.49 
Foerster, S. R. (1994). Stock Market Performance and Elections: Made-in-Canada Effects? Canadian Investment Review, (Summer), 39-42.

Foerster, S. R., \& Schmitz, J. J. (1997). The Transmission of U.S. Election Cycles to International Stock Returns. Journal of International Business Studies, 28, 1-27. https://doi.org/10.1057/palgrave.jibs.8490089

Goodell, J. W., \& Bodey, R. A. (2012). Price-Earnings Changes during US Presidential Election Cycles: Voter Uncertainty and Other Determinants. Public Choice, 150, 633-650. https://doi.org/10.1007/s11127-010-9720-8

Herbst, A. F., \& Slinkman, C. W. (1984). Political-Economic Cycles in the U.S. Stock Market. Financial Analysts Journal, 4O(2), 38-45. https://doi.org/10.2469/faj.v40.n2.38

Hobbs, G. R., \& Riley, W. B. (1984). Profiting from the Presidential Election. Financial Analysts Journal, 40(2), 46-53. https://doi.org/10.2469/faj.v40.n2.46

Hong, S., \& Xi, Y. (2016, November 9). Reason Gets Trumped on Chinese Stock Market During U.S. Election. The Wall Street Journal. Retrieved from http://blogs.wsj.com/chinarealtime/2016/11/09/reason-gets-trumped-on-chinese-stock-market-during-u-s-el ection

Huang, R. D. (1985). Common Stock Returns and Presidential Elections. Financial Analysts Journal, 41, 58-61. https://doi.org/10.2469/faj.v41.n2.58

Hung, L. C. (2011). Presidential Election and Stock Market in Taiwan. Journal of Business and Policy Research, $6,38-51$.

Hung, L. C. (2013). U.S. Presidential Elections and the Taiwanese Stock Market. Issues \& Studies, 49, 71-97.

Li, J., \& Born, J. A. (2006). Presidential Election Uncertainty and Common Stock Returns in the United States. Journal of Financial Research, 29, 609-622. https://doi.org/10.1111/j.1475-6803.2006.00197.x

Niederhoffer, V., Gibbs, S, \& Bullock, J. (1970). Presidential Elections and the Stock Market. Financial Analysts Journal, 26, 111-113.

Nippani, S., \& Arize, A. (2005). U.S. Presidential Election Impact on Canadian and Mexican Stock Markets. Journal of Economics and Finance, 29, 271-279. https://doi.org/10.1007/BF02761558

Nippani, S., \& Medlin, W. B. (2002). The 2000 Presidential Election and the Stock Market. Journal of Economics and Finance, 26, 162-169. https://doi.org/10.1007/BF02755983

Pantzalis, C., Stangeland, D. A., \& Turtle, H. J. (2000). Political Elections and the Resolution of Uncertainty: The International Evidence. Journal of Banking and Finance, 24, 1575-1604. https://doi.org/10.1016/S0378-4266(99)00093-X

Peteroff, N. (2016, November 11). Bull market! Chinese stocks up 21\% since January panic. CNN Money. Retrieved from http://money.cnn.com/2016/11/11/investing/china-shanghai-composite-bull-market-stocks

Shen, L. (2015, October 11). Meet the mom-and-pop investors of China's stock market. Business Insider. Retrieved from http://www.businessinsider.com/chinas-stock-market-investors-2015-10

\section{Notes}

Note 1. See for example: (1) "Bull market! Chinese stocks up $21 \%$ since January panic" http://money.cnn.com/2016/11/11/investing/china-shanghai-composite-bull-market-stocks/ (2) "Meet the mom-and-pop investors of China's market" http://www.businessinsider.com/chinas-stock-market-investors-2015-10 and (3) "Reason Gets Trumped on Chinese Stock Market During U.S.” Election": http://blogs.wsj.com/chinarealtime/2016/11/09/reason-gets-trumped-on-chinese-stock-market-during-u-s-electio $\mathrm{n} /$

Note 2. "Reason Gets Trumped on Chinese Stock Market During U.S. Election": https://blogs.wsj.com/chinarealtime/2016/11/09/reason-gets-trumped-on-chinese-stock-market-during-u-s-electio $\mathrm{n} /$

Note 3. Same as note 2. 


\section{Copyrights}

Copyright for this article is retained by the author(s), with first publication rights granted to the journal.

This is an open-access article distributed under the terms and conditions of the Creative Commons Attribution license (http://creativecommons.org/licenses/by/4.0/). 